\title{
The Shear Strength Characteristics of Red Clay
}

\author{
Kai sheng Chen ${ }^{1, a^{*}}$, Zhen $\mathrm{Lu}^{2, \mathrm{~b}}$ \\ ${ }^{1}$ School of Civil Engineering, Guizhou University Guizhou Guiyang China \\ ${ }^{2}$ School of Civil Engineering, Guizhou University Guizhou Guiyang China \\ achen_kaisheng@163.com, 'bu_zhenqiaosui@163.com \\ *chen_kaisheng@163.com
}

Keywords: red clay;direct shear test;shear strength characteristics

\begin{abstract}
The paper is aimed at the phenomenon of red clay subgrade disease,taking the subgrade filling from the Yuqing-Kaili Expressway as the research object, the soil mechanics as the theoretical foundation, the testing technology of geotechnical engineering as the method, resrearched the change regulation of the strength characteristics of red clay。 The research findings not only has the important academic value for improving the evaluation system of red clay road, but also has some engineering practical significance to the highway construction in the red clay area, Besides this, it can provide technology reference for other industries.
\end{abstract}

\section{Foreword}

The red clay has high moisture content, high plasticity, high void ratio and other special engineering properties, and there is more rain in South China, during the drying and wetting cycle, the long-term strength and stability of red clay subgrade descend, caused the subgrade to have some disease,as subgrade settlement,pavement crack,transverse crack,shoulder collapse,slope sliding,collapse and landslide.So it is has great important meaning to research the strength characteristics of red clay.

\section{Basic physical properties of Red clay}

Field Sampling. The red clay used in this experiment is from Yuqing-Kaili Expressway。 Thsee red clay's colors are brown red, brown red and brown yellow. The soil taking form subgrade is a little dry, and uniform, these soil's structure is compact; The soil taking form cutting slope is a little damp and loose, the amount of pieces of leaves and plant root tip in these soil is very little.Form the analysis of the particle compositicle,find ing the soil sample is mianly clay. The natural water content is high, the viscosity property is strong, the void ratio is big,the liquid limit is a little higher and in the soft plastic state.

\section{Basic physical properties of Red clay}

Table1 Basic physical properties of red clay

\begin{tabular}{|c|c|c|c|c|c|}
\hline \multirow{2}{*}{ JTG E40-2007 } & $>0.075 \mathrm{~mm}(\%)$ & $0.074 \sim 0.002 \mathrm{~mm}(\%)$ & \multicolumn{2}{|c|}{$<0.002 \mathrm{~mm}(\%)$} \\
\cline { 2 - 6 } & 17.25 & \multicolumn{2}{|c|}{71.41} & \multicolumn{2}{c|}{1.34} \\
\hline $\begin{array}{c}\text { Optimum moisture } \\
\text { content(\%) }\end{array}$ & $\begin{array}{c}\text { Plastic } \\
\text { limit }(\%)\end{array}$ & $\begin{array}{c}\text { Liquid } \\
\text { limit }(\%)\end{array}$ & $\begin{array}{c}\text { Plasticity } \\
\text { Index }\end{array}$ & Proportion & $\begin{array}{c}\text { Maximum dry unit } \\
\text { weight }(\mathrm{g} / \mathrm{cm} 3)\end{array}$ \\
\hline 37.2 & 38 & 59 & 21 & 2.720 & 1.46 \\
\hline
\end{tabular}




\section{Testing Program Sample Preparation}

Table2 Sample preparation

\begin{tabular}{|c|c|c|c|c|}
\hline Moisture content/\% & \multicolumn{4}{|c|}{ Degree of Compaction/\% } \\
\hline 30 & 75 & 85 & 90 & 96 \\
\hline 34 & 75 & 85 & 90 & 96 \\
\hline 37.2 & 75 & 85 & 90 & 96 \\
\hline 40 & 75 & 85 & 90 & 96 \\
\hline 44 & 75 & 85 & 90 & 96 \\
\hline
\end{tabular}

Test Method.When the soil sample prepared, do the unconsolidated-undrained triaxial shear test, set the vertical stress as $100 \mathrm{kpa}, 200 \mathrm{kpa}, 300 \mathrm{kpa}$ and $400 \mathrm{kpa}$, and the shear rate is $0.8 \mathrm{~mm} / \mathrm{min}$. When the shear displacement value reach $4 \mathrm{~mm}$,press the pause button and write down the damage value; When the process of shear without peak value, should shear until the displacement value reach $6 \mathrm{~mm}$. And taking the shear stress as the longitudinal coordinate, the shear displacement as the horizontal coordinate, then draw the shear stress-displacement curve, at last calculate cohesion value and angle of internal friction.

\section{Experime nt Result}

\section{Shear stress-dis placement curve}
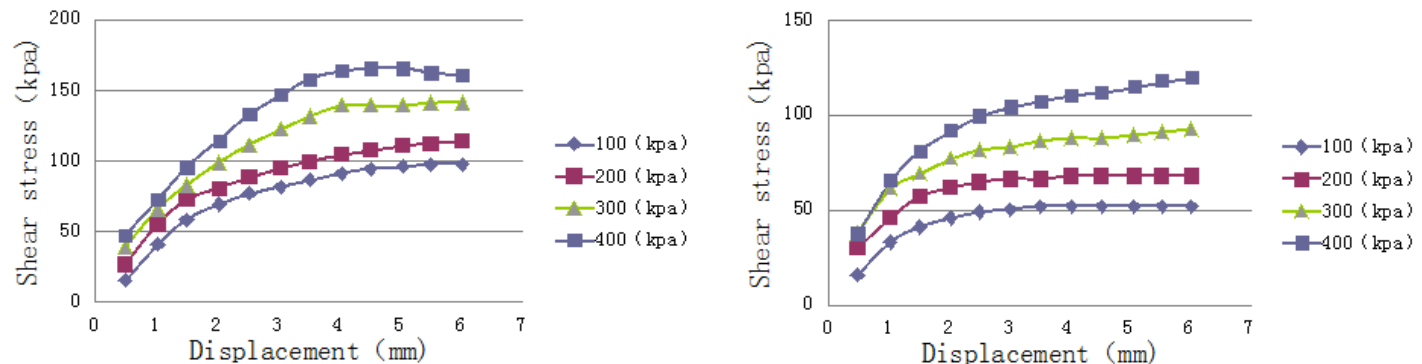

(a) $k=75 \%, \omega=30 \%$

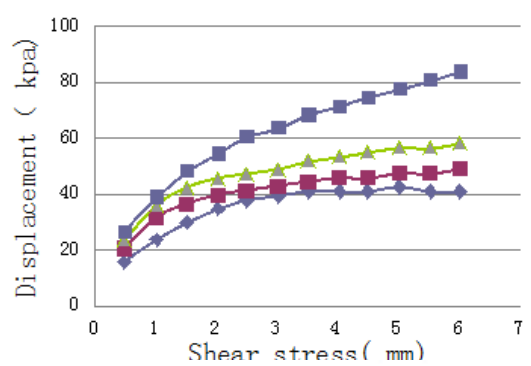

(b) $k=75 \%, \omega=34 \%$

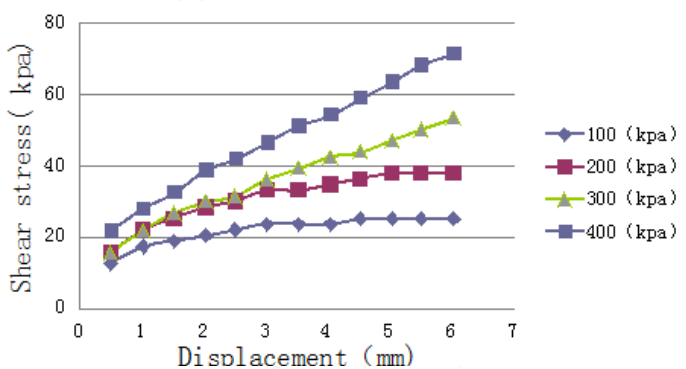

(c) $k=75 \%, \omega=37.2 \%$

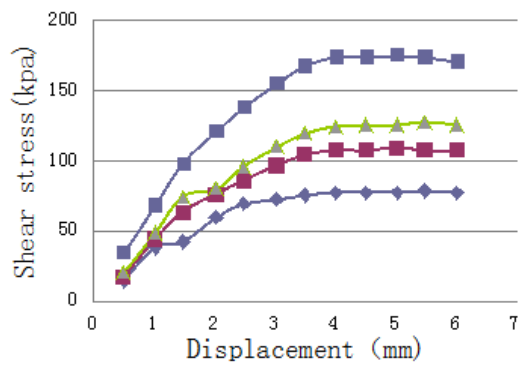

(d) $\mathrm{k}=75 \%, \omega=40 \%$

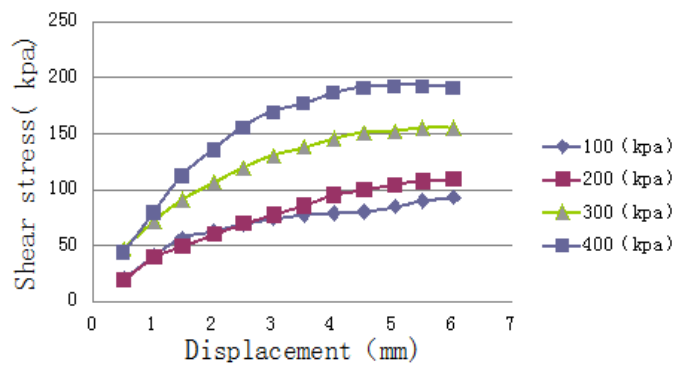

(e) $\mathrm{k}=75 \%, \omega=44 \%$
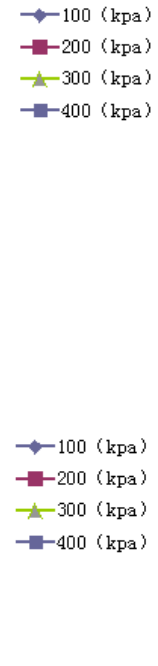

(f) $\mathrm{k}=85 \%, \omega=30 \%$ 


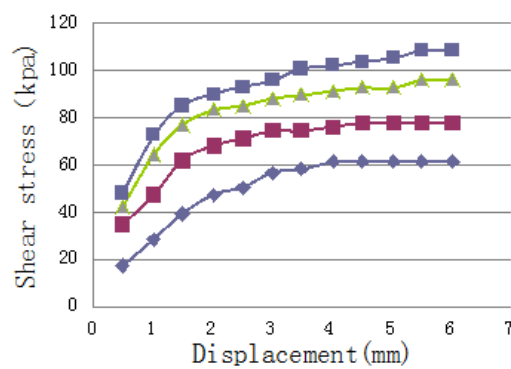

(g) $\mathrm{k}=85 \%, \omega=34 \%$

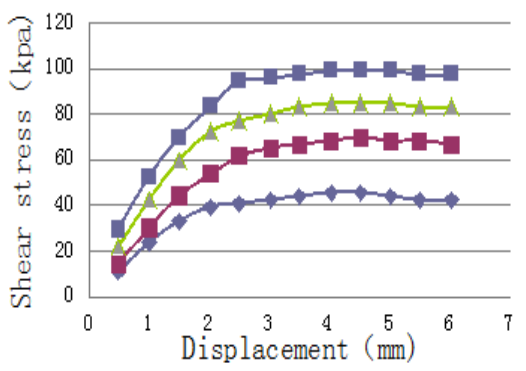

(i) $\mathrm{k}=85 \mathrm{x}, \omega=40 \%$

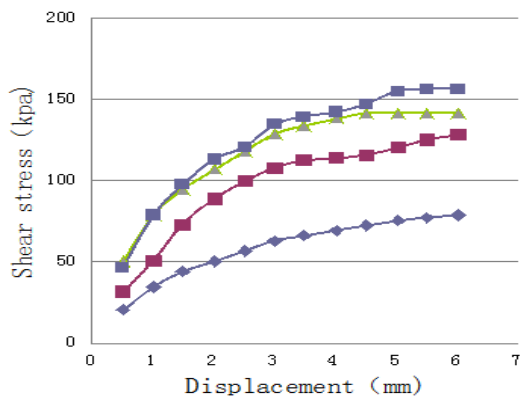

(k) $\mathrm{k}=90, \omega=30 \%$

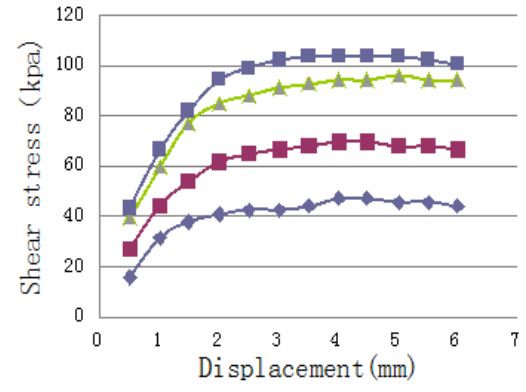

(m) $\mathrm{k}=90 \%, \omega=37.2 \%$

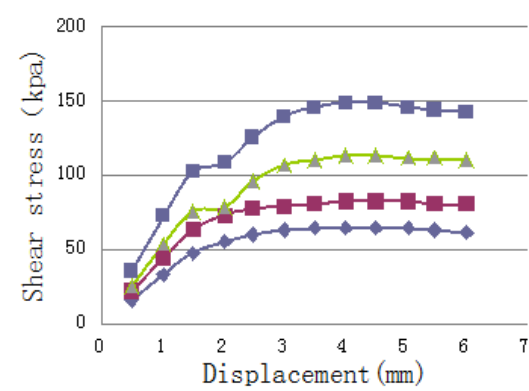

(o) $\mathrm{k}=90 \%, \omega=44 \%$

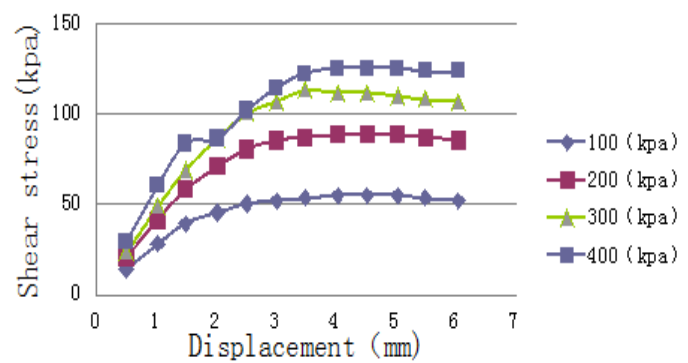

(h) $\mathrm{k}=85 \%, \omega=37.2 \%$

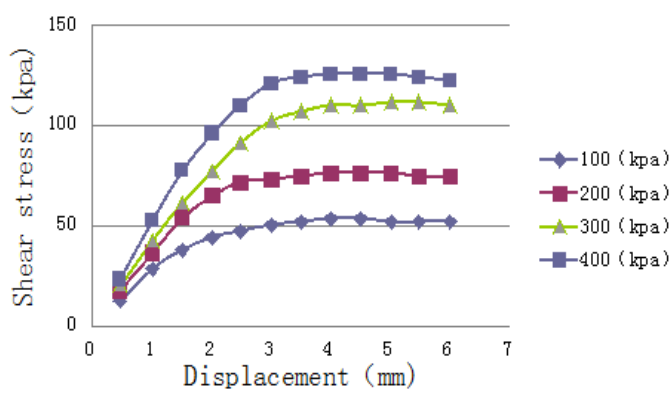

(j) $\mathrm{k}=85 \%, \omega=44 \%$

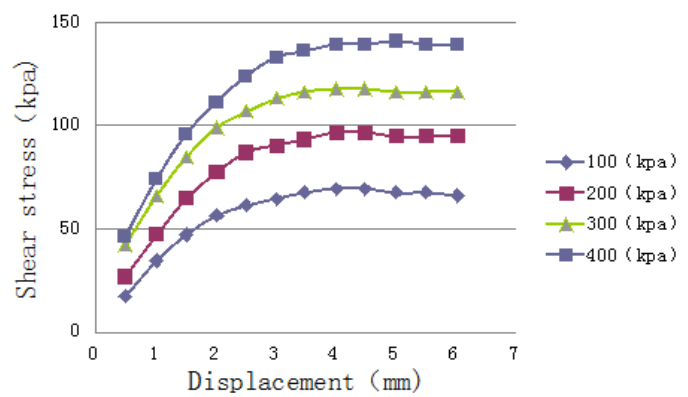

(1) $\mathrm{k}=90 \%, \omega=34 \%$

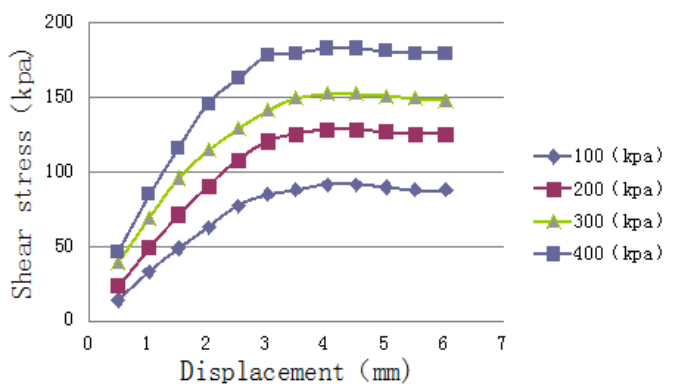

(n) $\mathrm{k}=90 \mathrm{x}, \omega=40 \%$

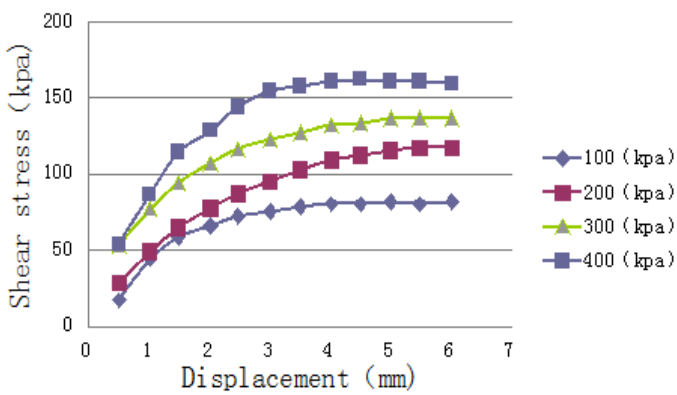

(p) $k=96 \%, \omega=30 \%$ 


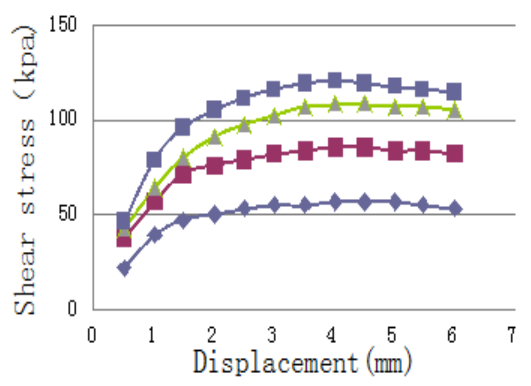

(k) $\mathrm{k}=968, \omega=34 \%$

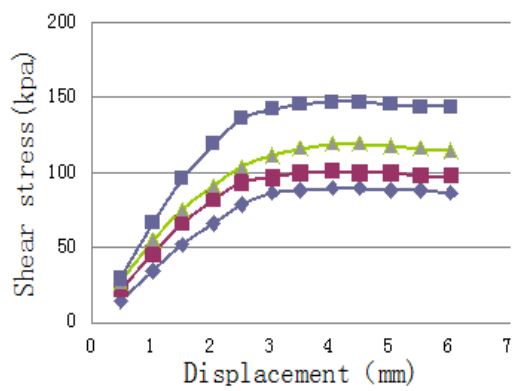

(s) $\mathrm{k}=96 \%, \omega=40 \%$
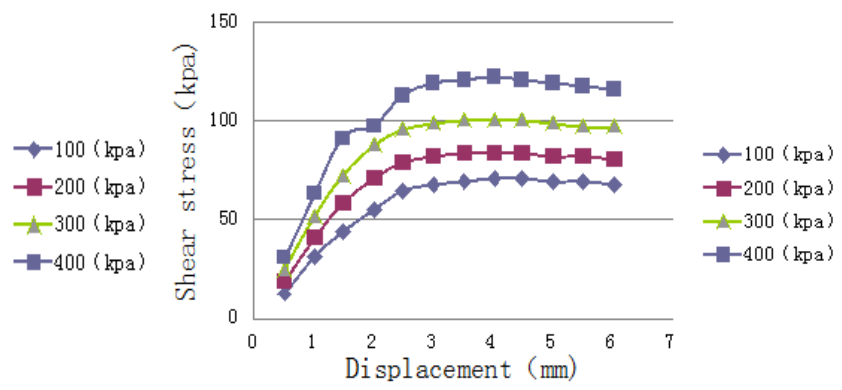

$(x) \mathrm{k}=968, \omega=37.2 \%$

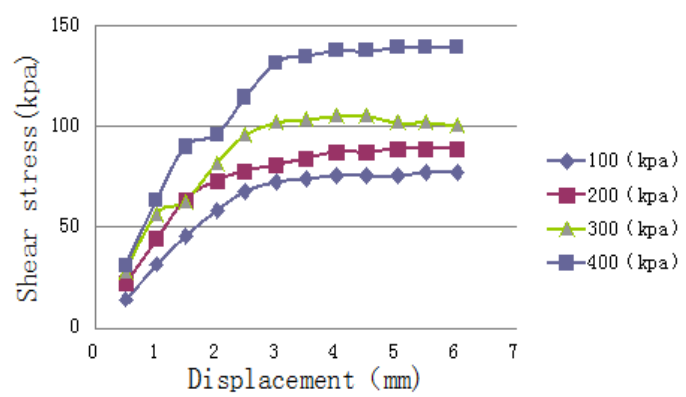

(t) $\mathrm{k}=968, \omega=44 \%$

Fig. 1 Shear stress-displacement curve

Form these curves, we can find Shear stress-displacement curve is begin steep, when the strain reached a certain value the curve is begin smooth,there is no peak value,it's appear as weakly hardening type.

Shear strength index-Moisture conten curve,shear strength index-Degree of compaction curve

(1) Shear Strength Index

Table 3 Cohesion value c (kpa)

\begin{tabular}{|c|c|c|c|c|}
\hline \multirow{2}{*}{$\begin{array}{c}\text { Moisture } \\
\text { conten/\% }\end{array}$} & \multicolumn{4}{|c|}{ Degree of Compaction/\% } \\
\cline { 2 - 5 } & 75 & 85 & 90 & 96 \\
\hline 30 & 38.23 & 52.73 & 56.24 & 64.48 \\
\hline 34 & 26.44 & 47.24 & 52.23 & 60.25 \\
\hline 37.2 & 23.71 & 45.26 & 50.24 & 55.21 \\
\hline 40 & 8.61 & 42.03 & 47.26 & 52.36 \\
\hline 44 & 17.42 & 37.02 & 41.12 & 47.24 \\
\hline
\end{tabular}

Table4 The angle of internal friction $\varphi_{\left({ }^{\circ}\right)^{\prime}}$

\begin{tabular}{|c|c|c|c|c|}
\hline \multirow{2}{*}{$\begin{array}{c}\text { Moisture } \\
\text { conten/\% }\end{array}$} & \multicolumn{4}{|c|}{ Degree of Compaction/\% } \\
\cline { 2 - 5 } & 75 & 85 & 90 & 96 \\
\hline 30 & 14.47 & 17.36 & 19.35 & 21.23 \\
\hline 34 & 12.73 & 16.02 & 18.21 & 19.75 \\
\hline 37.2 & 7.79 & 14.02 & 17.23 & 17.53 \\
\hline 40 & 8.72 & 11.32 & 13.02 & 15.02 \\
\hline 44 & 11.24 & 9.81 & 10.89 & 11.89 \\
\hline
\end{tabular}

(2) The relationship between shear strength index with Moisture conten,the relationship between shear strength index with Degree of compactness

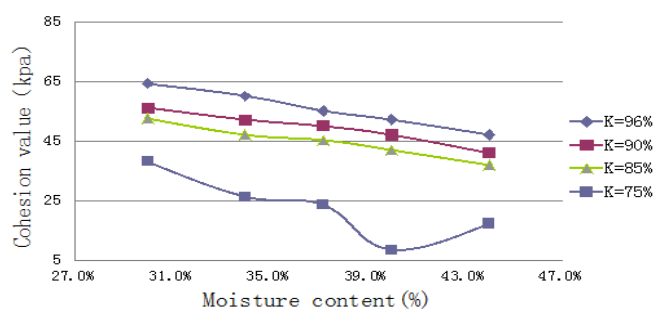

Fig. 2 Cohesion value -Moisture content curve

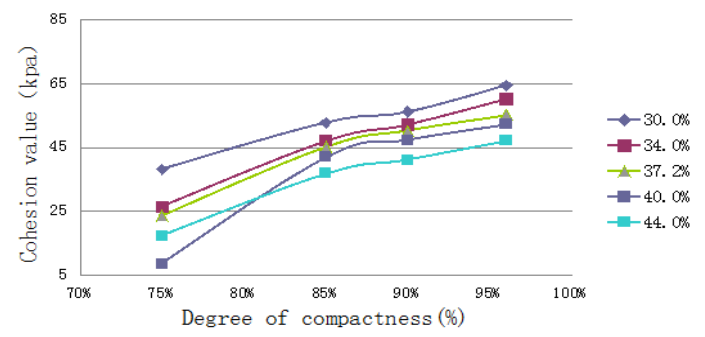

Fig.3 Cohesion value -Degree of compactness curve 


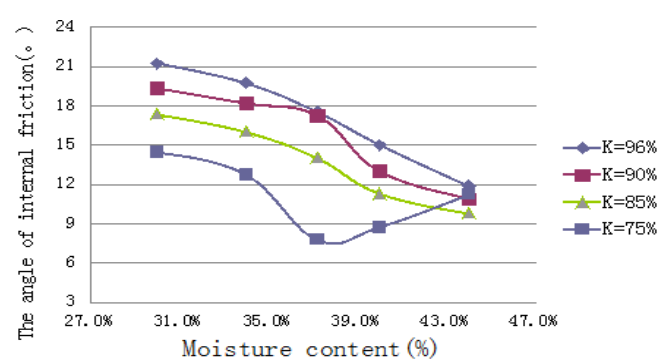

Fig.4 The angle of internal frictionMoisture content curve

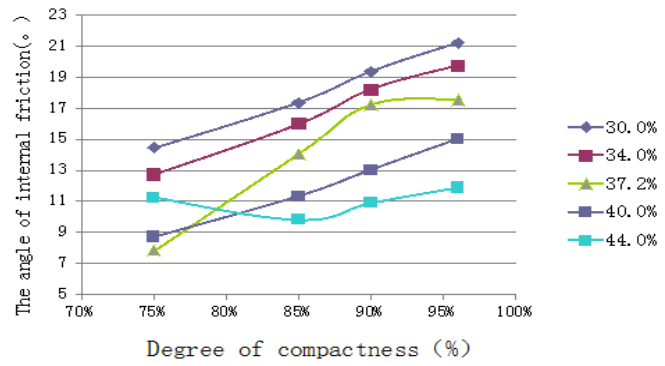

Fig.5 The angle of internal frictionDegree of compactness curve

\section{Conclusion}

(1) The cohesion value c decreases monotonically with the increase of moisture conten ${ }^{\omega}$, and increases monotonically with the increase of the degree of compactness $\mathrm{k}$.

(2) The angle of internal friction decreases monotonically with the increase of the moisture content $^{\omega}$, and increases monotonically with the increase of the degree of compactness $\mathrm{k} .$.

(3) The amplitude of cohesion value $C$ varies with the change of moisture conten ${ }^{\omega}$ and degree of compactness $\mathrm{K}$ than that of angle of internal friction.

\section{Acknowledge ments}

This work was financially supported by National Natural Science Foundation of China (Approval number:51368010)and Guizhou science and Technology Department - Guizhou University Foundation(Qiankehe Lh zi[2014]).

\section{References}

[1]Zhihong Huang,Lijun Zhu, Yiling Liao.Mechanical Properties Of Red Clay Under Different Stress Paths[J]. Journal of Rock Mechanics and Geotechnical Engineering , 2004 , 23(15):2599-2603

[2]Zhizheng Xiao,Baoshen Liu.Experimental study on the Mechanical Strength of Residual Laterite[J].Journal of Underground Space and Engineering, 2005，1(7):990-993

[3]Qingtao Bi, Guoping Jiang, Shuyun Ding.Water Content Influence On The Shearing Strength On Red Clay[J].Journal of Earth and Environment, 2005，33(3):144-147

[4]Jingyang Li.Mechanical Strength of Residual Laterite in Guizhou[J].Journal of Guizhou University of Technology,1997, 26(2):73-78

[5]Chun $\mathrm{LIu}, \mathrm{XuChun} \mathrm{Wu}$.Research of the strength characteristics of unsaturated red clay based on general tri-axial test.[J].Journal of Building Science Research of Sichuan.2003，29(2):65-73.

[6]Kaisheng Chen, Yuan Yin.Experimental Research of Strength Index of Red Clay for Guiyang-Qingzhen Expressway [J]. Journal of Highway and Transportation Research and Development, 2011, 28(3) : 61-66

[7]Heping Yang,Rui Zhang,Jianlong Zheng. Variation of deformation and strength ofexpansive soil during cyclic wetting and drying under loading condition $[\mathrm{J}]$. Geotechnical Engineering, 2006, 28(11):1936-1941 